\title{
ESTUDO DAS CONDIÇÕES GERAIS DA BARRAGEM DE ITANS NO MUNICÍPIO DE CAICÓ/RN - ESTUDO DE CASO
}

\author{
WESLEY ARTUR. SANTOS \\ Aluno de Graduação \\ Universidade Federal Rural do Semiárido \\ Rio Grande do Norte, Brasil \\ Wesleyartur-tw@hotmail.com \\ FRANCISCA SARA. MELO \\ Aluna de Graduação \\ Universidade Federal Rural do Semiárido \\ Rio Grande do Norte, Brasil \\ Saravieira123vieirasara@ hotmail.com
}

\author{
MARCILENE. NÓBREGA \\ Professora Dra. do Magistério Superior \\ Universidade Federal Rural do Semiárido \\ Rio Grande do Norte, Brasil \\ marcilenenobrega@ufersa.edu.br
}

\section{RESUMO}

As barragens são construções utilizadas pelas civilizações ao longo dos anos, possuindo diversas finalidades. Apesar dessas estruturas gerarem vários benefícios, podem possuir alto potencial de risco em caso de colapso, causando consequências catastróficas, tanto ao meio ambiente quanto a vida humana, caso não sejam monitoradas e não passem por manutenções periódicas. O estado do Rio Grande do Norte possui catalogadas pela Agência Nacional de Águas (ANA), 619 reservatórios. Dentro desse número, tem-se os grandes e pequenos reservatórios. Esses grandes e pequenos reservatórios são importantes para combater a escassez hídrica que sofre a maior parte do estado Dentre estes são considerados motivo de preocupação principalmente os pequenos, que somam mais de dez mil onde não são catalogados e a maioria não possui nenhuma normativa técnica.. Diante disso, este trabalho teve como objetivo principal realizar um levantamento das condições gerais da Barragem de Itans, localizada no município de Caicó/RN. Para tal, foi elaborado um estudo contendo o histórico construtivo da barragem ao longo de sua vida útil e realizada visitas in loco para identificar possíveis anomalias presentes na mesma. As principais anomalias observadas nos taludes de jusante e montante e na crista da barragem foram: malha asfáltica danificada, meio fio danificado, saídas d'água com rachaduras, presença de vegetações e de árvores pequenas até de porte médio nos taludes, canaletas de drenagem obstruídas e com trincas. Sugerem-se reparos simples nessas anomalias para que a barragem consiga enfrentar os períodos de cheias com segurança.

Palavras-chave: Barragem de Terra, Anomalias, Recursos Hídricos.

\section{ABSTRACT}

Dams are structures used by civilizations over the years because of their many purposes. Although they generate many benefits, they can have a high risk potential in the event of a collapse, causing catastrophic consequences to both the environment and human life if they are not monitored and not undergo periodic maintenance. The state of Rio Grande do Norte cataloged six hundred and nineteen (619) dams of the National Water Agency (ANA). Within this large number are the large and small reservoirs. The large dams of the state did not present problems, being of concern mainly small ones, which add up to more than ten thousand and most do not have any technical regulations. These large and small dams are important to counter the water shortages that suffer most of the state. In view of this, this work had as main objective to carry out a survey of the general conditions of the Itans Dam, located in the city of Caicó/RN. For this purpose, a study was carried out containing the constructive history of the dam along its useful life and carried out on-site visits to identify possible anomalies present in the dam. The main anomalies observed in the slopes of downstream, upstream and on the crest of the dam were: damaged asphalt mesh, damaged curb, cracks in water sluices, presence of vegetation and small to medium-sized trees on slopes, blocked and cracked drainage channels. It is suggested to repair these anomalies so that can face periods of full dam safely

Keywords: Earth dam. Anomalies. water resources. 


\section{INTRODUÇÃO}

Sendo uma das alternativas para suprir a necessidade de água durante os períodos de estiagem no semiárido brasileiro, as barragens de terra têm papel importante para vivência do povo nordestino. São utilizadas em diversas atividades como, por exemplo, irrigação, pecuária, pesca e uso doméstico (CGEE, 2015).

A barragem de terra é uma estrutura executada no sentido transversal ao curso d'água, fazendo com que seja formado um reservatório artificial. As mesmas são formadas principalmente por solo. Existem dois tipos: homogêneas e zonadas. Quando ocorre a predominância apenas de um tipo de material, a barragem é dita homogênea, apesar de que, pode haver existência de elementos diversificados, como exemplo: filtros, rip-rap etc. No caso das zonadas existe um zoneamento de materiais terrosos que se dar através das características dos materiais e sua permeabilidade (COSTA, 2012).

As estruturas sofrem com a ação do tempo durante sua vida útil. Com as barragens não serião diferentes. E com estas ainda tem as consequências em função dos períodos longos de estiagem que podem gerar vários problemas denominados de anomalias. De acordo com o Manual do Empreendedor sobre Segurança de Barragens (2016), as anomalias mais frequentes em barragens de terra são: fissuras; surgências; instabilidade de taludes, recalques localizados; afundamentos (tipo sinkhole); proteção deficiente dos taludes; erosão superficial; ocorrência de árvores, arbustos e tocas de animais.

Para que esses problemas sejam evitados, é necessário que os reservatórios passem por manutenções e inspeções periódicas. Devido aos grandes desastres que aconteceram ao longo da história, se fez necessário criar a Lei $\mathrm{n}^{\circ}$ (12.334/2010) que tem como objetivo garantir a observância de padrões de segurança de barragens de maneira a reduzir a possibilidade de acidente e suas consequências.

Em consequência das últimas tragédias de maior repercussão que ocorreram no estado de Minas Gerais, como os rompimentos das barragens de Mariana/MG no ano de 2015 e Brumadinho/MG em 2019, houve uma preocupação maior em fiscalizar a segurança das barragens do estado do Rio Grande do Norte. Segundo Lemos (2019) , nenhum grande reservatório do estado apresenta risco elevado de rompimento, sendo o Itans um dos maiores do estado. Apenas os pequenos reservatórios são motivo de preocupação, eles são cerca de 10.000 (dez mil) espalhados pelo estado, sendo a maioria deles, sem conhecimento do poder público.

Com uma capacidade total de armazenamento de $81.750 .000 \mathrm{~m}^{3}$, a Barragem Itans, localizada na cidade de Caicó-RN é um dos maiores reservatórios do Estado do Rio Grande do Norte. Suas águas são utilizadas para o abastecimento da cidade, como também para prover a irrigação e ainda gerar renda com a atividade pesqueira. $\mathrm{O}$ açude faz o barramento das águas do Rio Barra Nova, onde é tributário da bacia hidrográfica Piranhas-Açu. O mesmo foi construído pelo Departamento de Obras Contra as Secas.

A construção da barragem trouxe muitos benefícios à população, com o surgimento de emprego, fez com que a economia aumentasse. Devido a construção dessa estrutura se teve um salto na viabilidade econômica e social da cidade, visto que a água ali presente passou a servir para diversos fatores como, irrigação, o abastecimento da população, das industrias, o combate contra a seca entre outros benefícios.

Considerando a importância econômica e social da Barragem de Itans, como também em função dos longos períodos de estiagem a que a mesma foi e é submetida, pesquisas são feitas para estudar as condições gerais da referida barragem.

\section{FUNDAMENTAÇÃO TEÓRICA}

\subsection{Considerações gerais sobre barragem}

De acordo com o Comitê Brasileiro de Barragens (2013), as barragens são obstáculos artificiais que tem capacidade de reter água ou qualquer outro líquido, rejeitos, detritos, que pode ter como finalidade o controle ou armazenamento. Podem ser de diversos tamanhos, desde pequenos maciços de terra, geralmente utilizadas em fazendas, até grandes barragens de concreto ou aterro, que tem normalmente como finalidade o fornecimento de água e de energia hidrelétrica, para controlar cheias e para diversas finalidades. 


\subsection{Anomalias em barragens de terra}

Toda construção está sujeita há problemas, havendo uma necessidade de identificá-los e tratá-los. Dentro de uma barragem de terra, ao longo da sua vida útil, podem aparecer anomalias que comprometam seu funcionamento trazendo riscos as populações no seu entorno.

Segundo o Manual do Empreendedor sobre Segurança de Barragens (2016), anomalia em barragem de terra, pode ser definida como qualquer deficiência, irregularidade, anormalidade ou deformação que possa prejudicar a segurança, em curto ou longo prazo. Para a análise das anomalias presentes é necessário identificar os tipos, saber o impacto na segurança da barragem e implementar ações para corrigir-lás.

\subsubsection{Erosão}

A crista é responsável por receber o tráfego de pessoas, veículos, animais, ação do vento e ainda e stá sujeito ao acúmulo d'água sobre a sua superfície proveniente das chuvas, o escoamento de água pode provocar erosão (Figura 1).

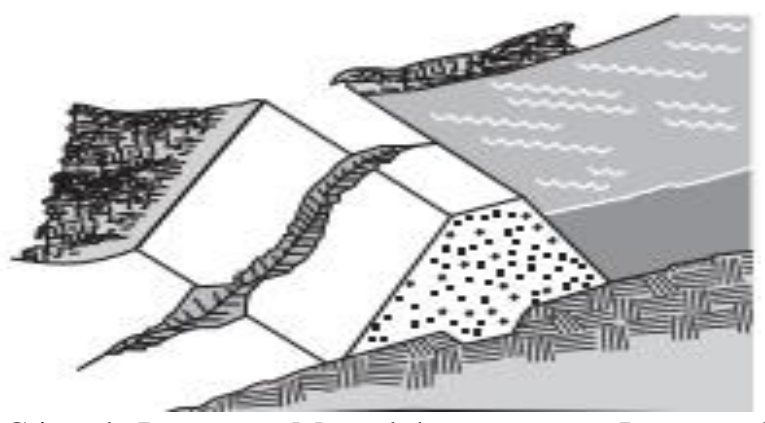

Figura 1: Erosão na Crista da Barragem. Manual de segurança e Inspeção de Barragens (2002)

\subsubsection{Fissuras transversais e longitudinais}

Outra anomalia que pode ocorrer são as fissuras transversais e longitudinais (Figura 2). Estas podem ocorrer devido há alguma falha existente na fundação e em consequência disso, cause a perda de estabilidade. É necessário possuir as informações da dimensão e local que se encontra. Para evitar os problemas decorrentes desse tipo de anomalia, como exemplos que podem surgir são: escorregamento, erosões internas e acomodações da fundação.

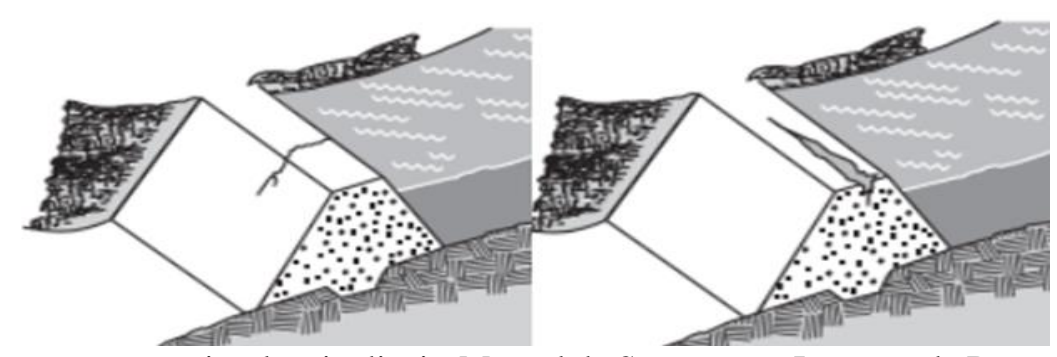

Figura 2: Fissuras transversais e longitudinais. Manual de Segurança e Inspeção de Barragens (2002)

Ainda de acordo com o Manual do Empreendedor sobre Segurança de Barragens (2016) essas fissuras podem ocorrer na malha asfáltica (Figura 3). Os possíveis causadores são: trações devido a recalques excessivos, deformações laterais do aterro e escarpas devido à instabilidade de taludes. 

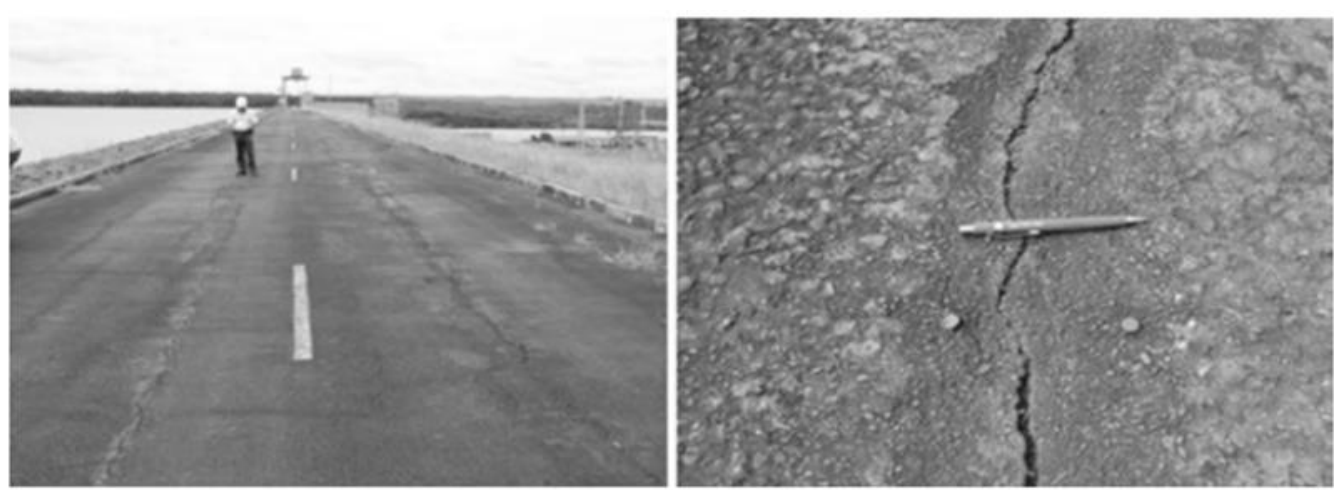

Figura 3: Fissuras transversais e longitudinais na malha asfáltica. SBB Engenharia / Banco de Imagens ANA (2015)

\subsubsection{Falha no revestimento}

A falha no revestimento também é uma anomalia presente na crista da barragem. Os causadores são: falha na drenagem, passagem de veículos e animais, degaste devido a ação do vento. Em decorrência disso podem causar erosões, provocando falhas no revestimento.

\subsubsection{Desabamento na crista da barragem}

Segundo o Manual de Segurança e Inspeções de Barragens (2002) podem acontecer desabamentos na crista (Figura 4), decorrente de ações de animais roedores ou pelo conduto da tomada d'água com problemas de vazamentos, provocando erosão no corpo da barragem.

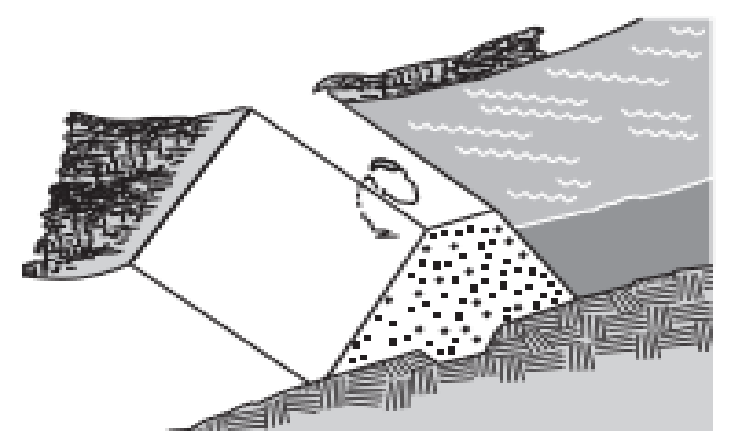

Figura 4: Desabamento na crista da barragem. Manual de segurança e Inspeções de Barragens (2002)

\subsubsection{Presença de Vegetação Excessiva}

Ainda de acordo com o mesmo, devido à falta de manutenção é natural o surgimento de árvores e arbustos ao longo do corpo do reservatório (Figura 5). Em barragens que não existem tráfegos de veículos é mais comum a existência desse tipo de anomalia, fazendo necessário conhecer a sua natureza, densidade e tamanho.

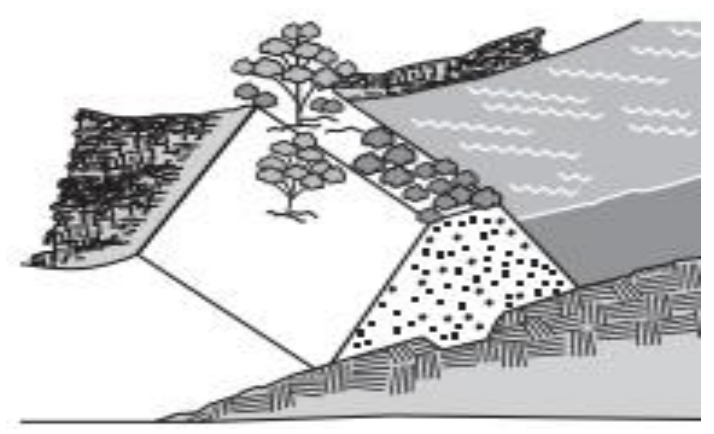

Figura 5: Presença de Vegetação Excessiva. Manual de Segurança e Inspeções de Barragens (2002) 


\subsubsection{Defeito na drenagem}

O defeito na drenagem pode trazer consequências para o escoamento da água, fazendo com que a água não escoe pelas caneletas de drenagem, surgindo como consequências poças d'água ou mesmo o escoamento diretamente pelos taludes. Isso pode ser causado devido a obstrução das caneletas devido a falta de manutenção (Manual do Empreendedor sobre Segurança de Barragens, 2016).

\section{MATERIAIS E MÉTODOS}

\subsection{Local da pesquisa}

O local escolhido para o estudo foi a Barragem de Itans, que fica localizada a $4 \mathrm{~km}$ da cidade de Caicó, no interior do Estado do Rio Grande do Norte. A cidade possui uma população de 67.554, segundo estimativa feita pelo IBGE (2018), sendo a sétima cidade mais populosa do estado. Na Figura 6 veem-se detalhes de toda extensão da Barragem estudada.

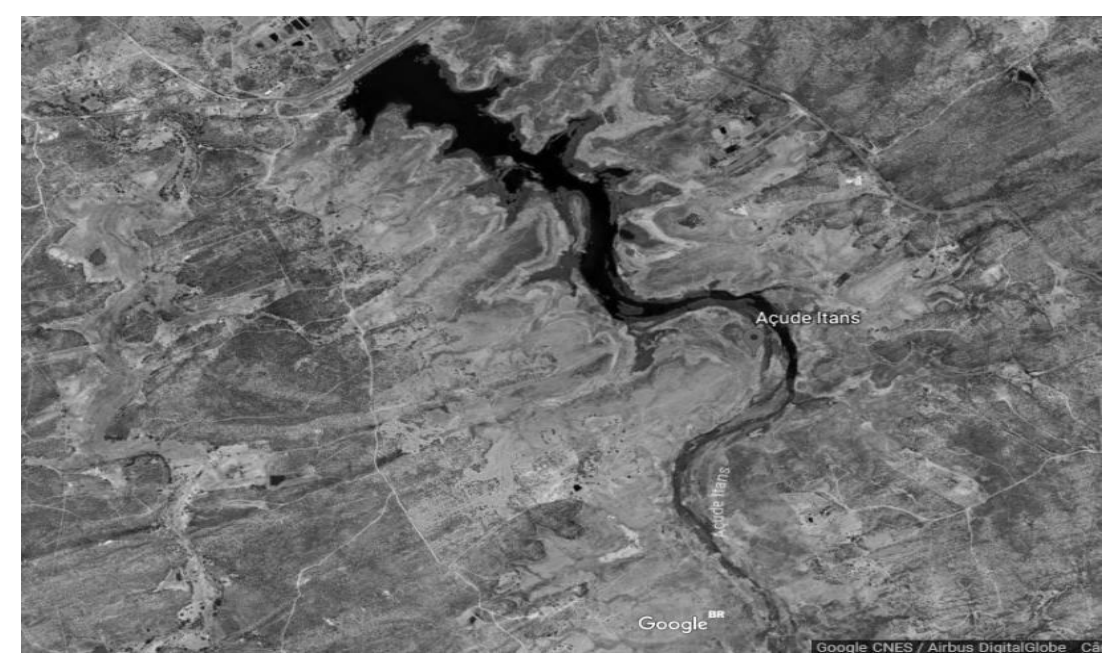

Figura 6: Barragem de Itans. Google (2019)

\subsection{Levantamento das anomalias}

Para o levantamento das anomalias presentes na barragem, foram realizadas inspeções visuais em toda sua estrutura e foram feitos registros fotográficos. Os elementos vistoriados foram a crista da barragem e os taludes de montante e jusante.

\section{RESULTADOS E DISCUSSÃO}

As principais anomalias observadas nos taludes de jusante e montante e na crista da barragem foram: malha asfáltica danificada com a presença de buracos e trincas; meio fio danificado ao longo do corpo, apresentando rachaduras e em alguns lugares totalmente danificados; a maioria das saídas d'água apresentavam rachaduras; nos taludes é visto a presença de vegetações e de árvores pequenas até de porte médio; as canaletas de drenagem obstruídas e algumas com presença de trincas. Nos itens seguintes serão detalhadas e descritas essas anomalias, separadas pela crista da barragem , taludes de jusante e montante.

\subsection{Resultados das anomalias presentes na crista da barragem}

\subsubsection{Malha Asfáltica}

Na crista da barragem, verificou-se a presença de falhas na malha asfáltica, como a presença de trincas (Figura 7) e de buracos (Figura 8). 


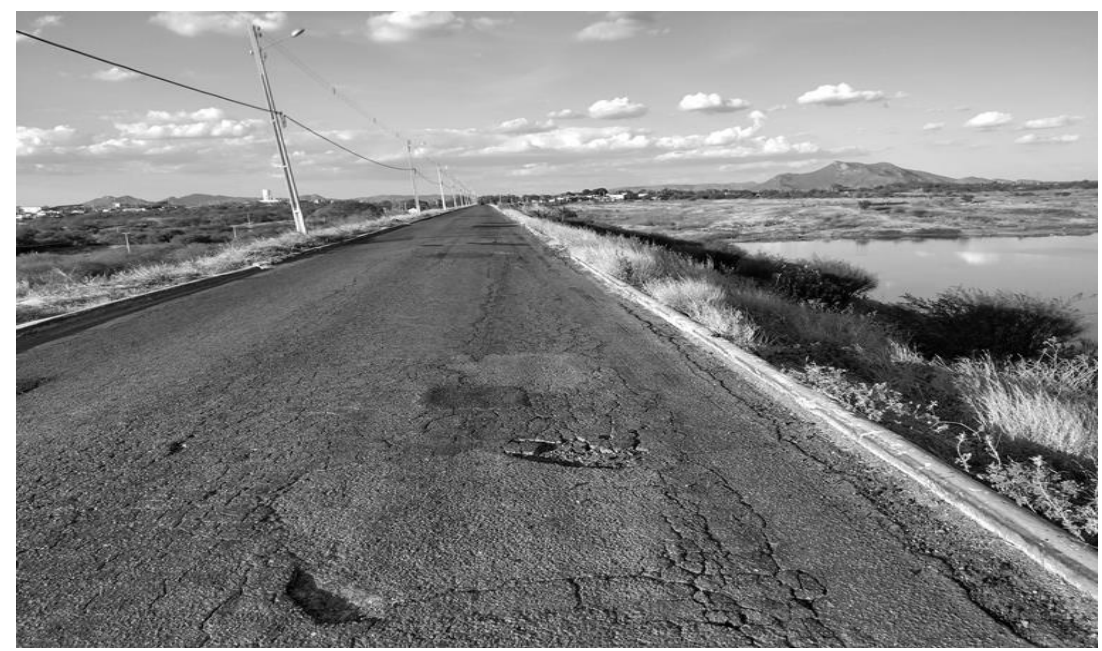

Figura 7: Malha asfáltica com falhas, com destaque para as trincas. Autoria própria (2019)

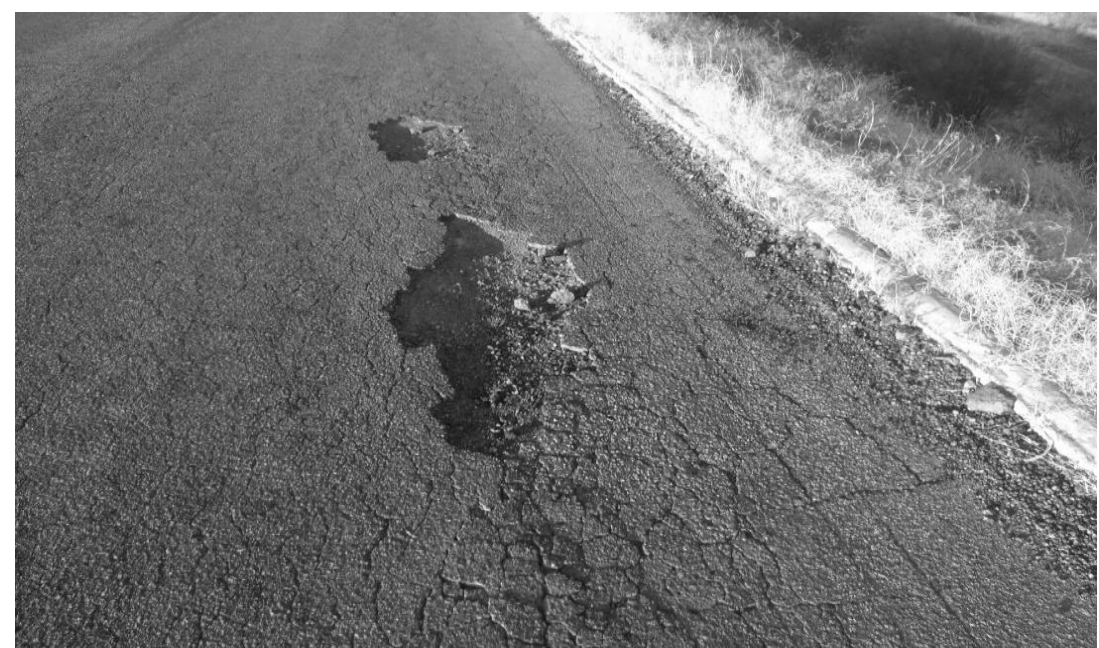

Figura 8: Buracos na malha asfáltica. Autoria própria (2019)

Um fator que pode estar acarretando esse desgaste na malha asfáltica da crista da barragem, é o tráfego intenso de veículos de pequeno, médio e grande porte, visto que a mesma está localizada na RN-118 que interliga os municípios de São João do Sabugi-RN a Caicó-RN.

Outro fator que pode está contribuindo é se o material utilizado para pavimentação não foi de boa qualidade e/ou as camadas de compactação não foram bem executadas.

Segundo o Manual de Segurança e Inspeção de Barragens (2002), a causa desse tipo de anomalia pode estar relacionada também com a escavação de animais; a presença de furos no conduto da tomada d'água, causando assim erosão do material da barragem e/ou devido infiltração provocando a erosão interna ou piping.

Esse desgaste, se não for reparado em tempo, pode ocasionar desabamentos, deslizamentos, instabilidade, como também reduzir a seção transversal do maciço da barragem e ainda penetrar água pela parte superficial, assim comprometendo a instabilidade do corpo da barragem.

\subsubsection{Meio Fio danificado}

Ao longo de toda extensão do meio fio, pode-se perceber que o mesmo sofreu danos, apresentando trincas e em alguns trechos completamente quebrado, em outros locais não existem mais. Na Figura 9 observa-se que o meio fio está completamente danificado, assim como em alguns trechos ao longo do corpo da barragem, onde já não existem mais a presença e foi completamente destruído, como é visto na Figura 10. 


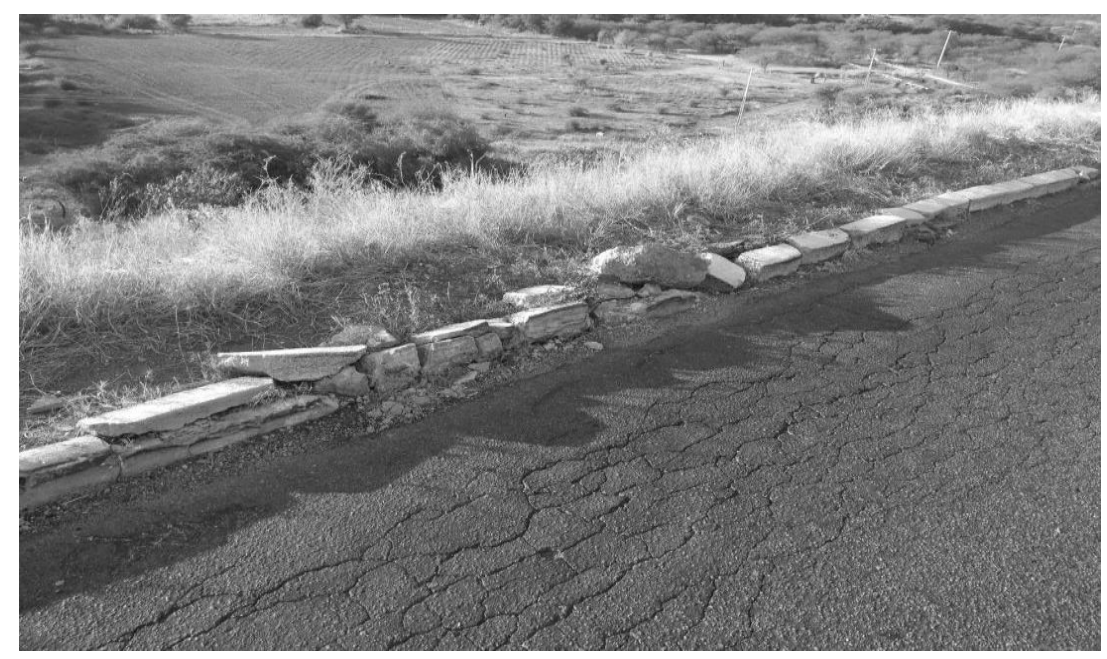

Figura 9: Meio fio danificado em um trecho da crista da barragem de Itans. Autoria propria (2019)

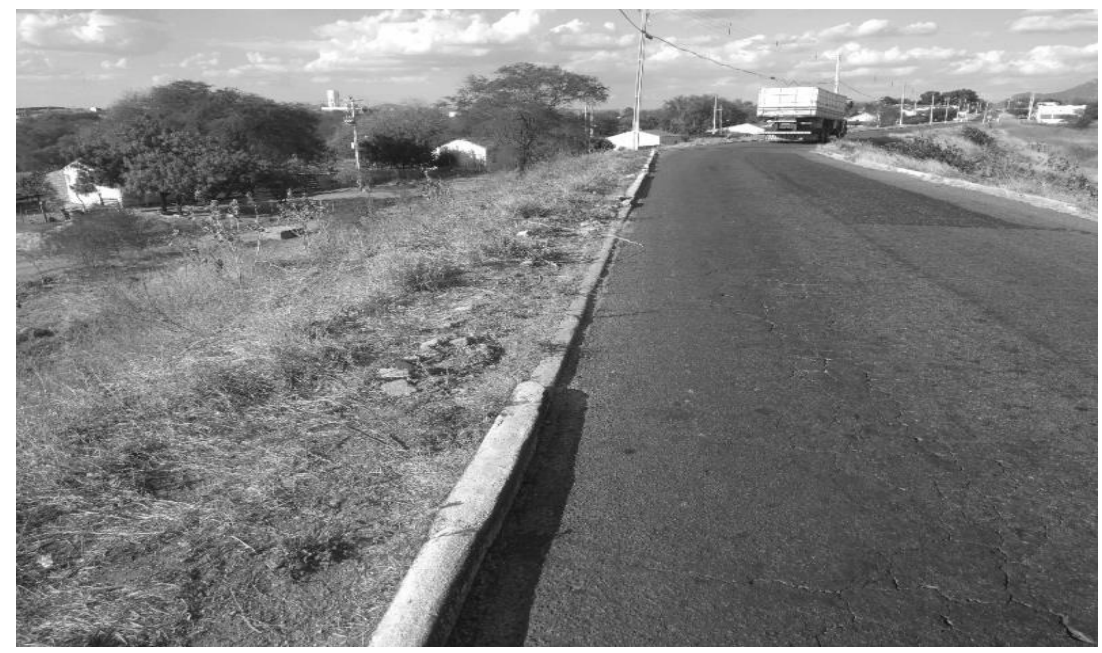

Figura 10: Detalhe da ausência de meio fio em um trecho da crista. Autoria propria (2019)

De acordo com o Manual do Empreendedor sobre Segurança de Barragens (2016), a causa dessa anomalia pode ter sido decorrida do mau funcionamento do sistema de drenagem, pelo carreamento do solo que serve de apoio e escorregamento do maciço.

\subsubsection{Problemas nas caneletas}

Diversas anomalias são apresentadas nas caneletas. Observa-se em várias delas, a obstrução da passagem d'água, trincas e algumas quebradas. Na Figura 11 é possível perceber que a caneleta está completamente obstruída, já na Figura 12 é encontrada a presença de trincas, e na Figura 13 buracos na sua entrada. 


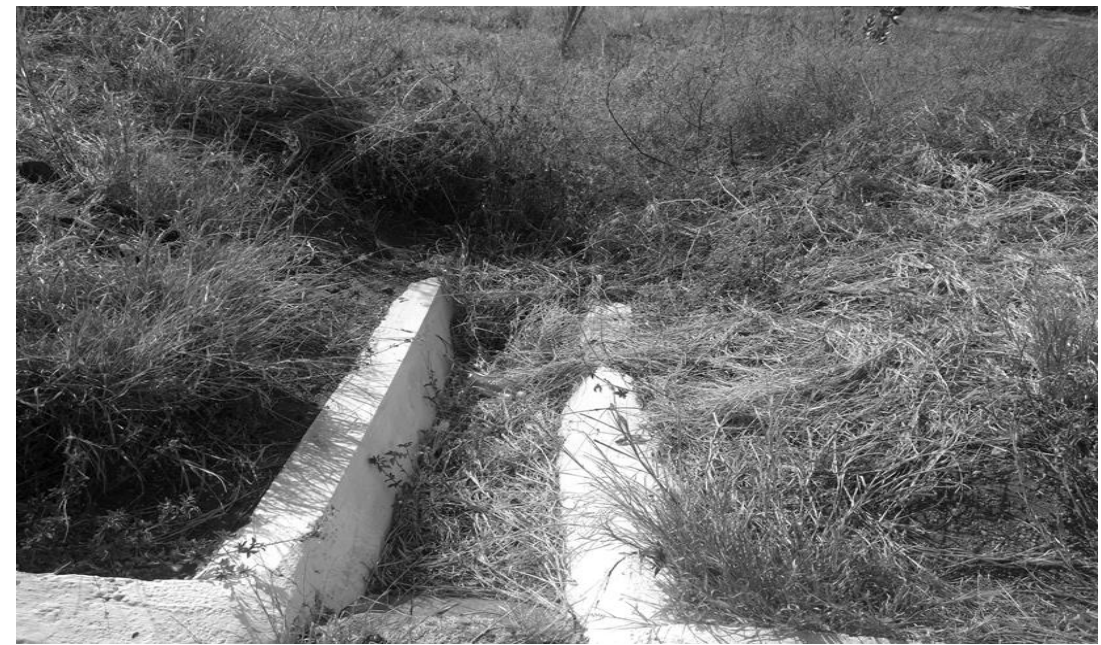

Figura 11: Caneletas obstruídas com vegetação. Autoria própria (2019)

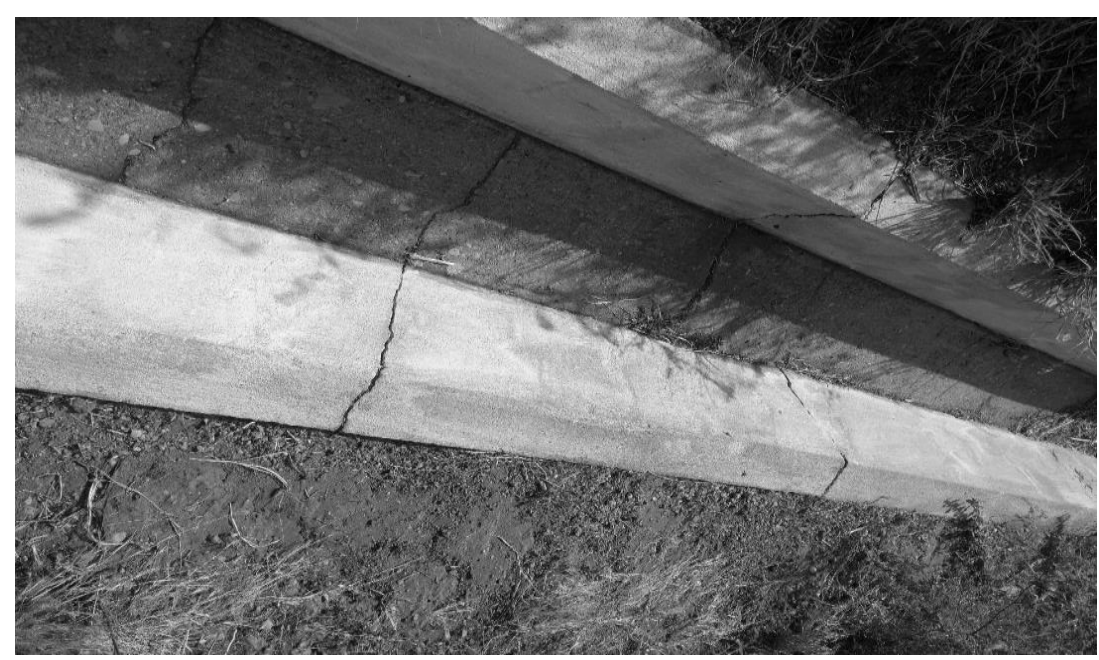

Figura 12: Presença de trincas nas caneletas. Autoria propria (2019)

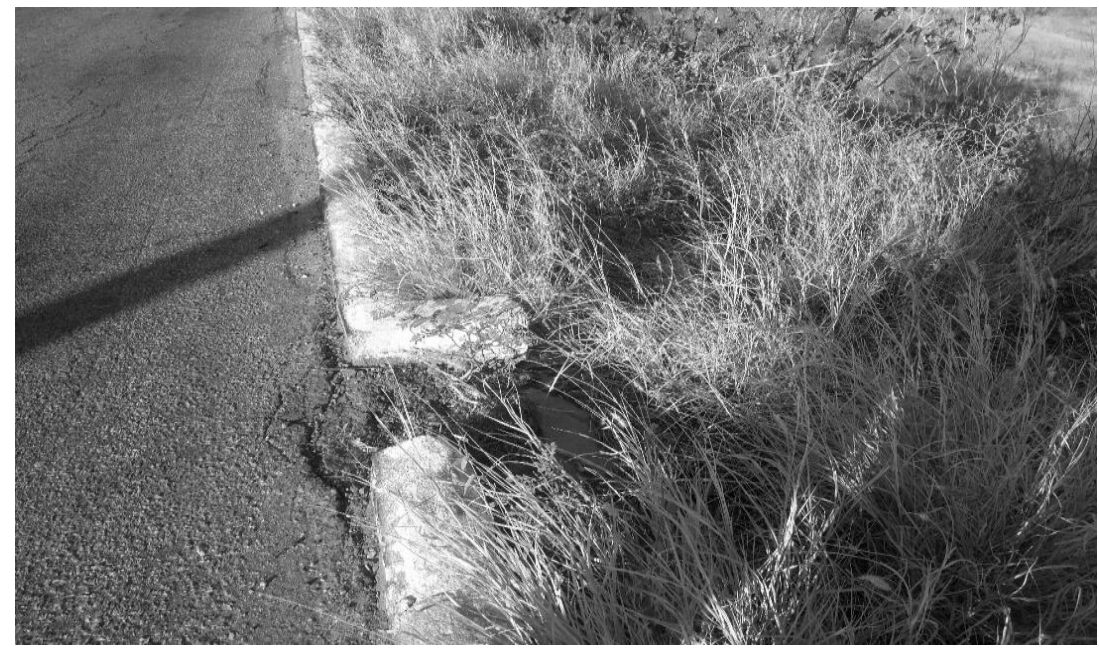

Figura 13: Caneletas quebradas e com obstrução da passagem de água por vegetação. Autoria própria (2019)

Ainda de acordo com o Manual do Empreendedor sobre Segurança de Barragens (2016), isso pode ocasionar o escoamento da água da chuva diretamente pelos taludes, não passando pelas caneletas, ocorrendo erosão no solo. 


\subsection{Resultados das anomalias presentes nos taludes de jusante e montante}

\subsubsection{Presença de vegetação}

Na barragem foi possível observar a presença de vegetação em diversos pontos dos taludes de montante e jusante, assim como no enrocamento de pedras. Pode-se perceber na Figura 14 a vegetação presente no talude de montante.

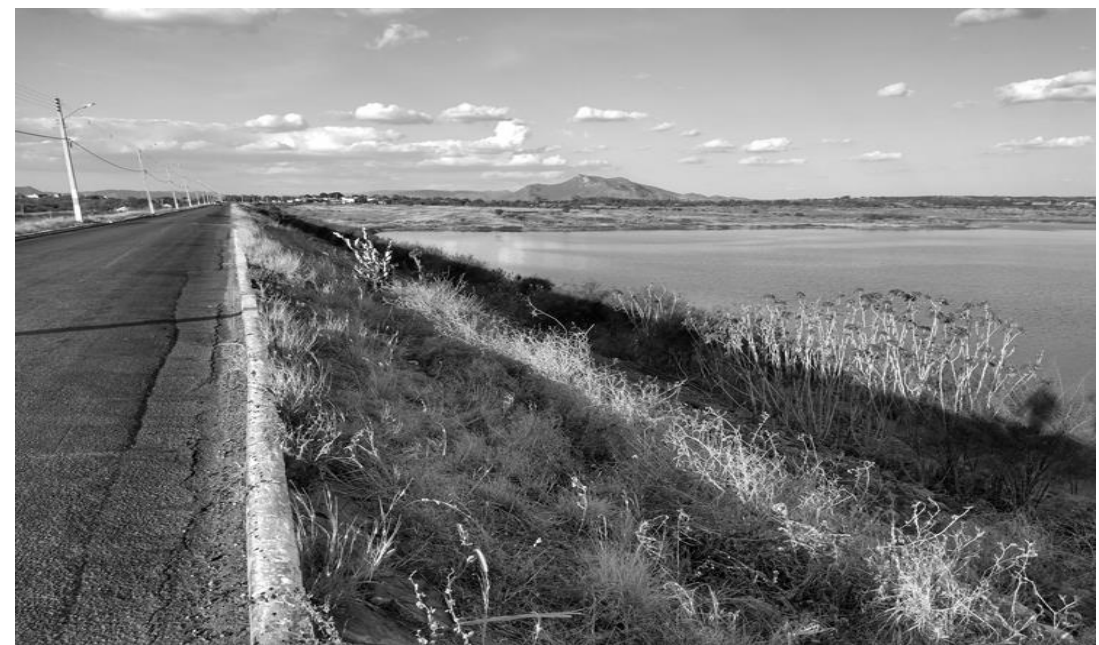

Figura 14: Surgimento de vegetação no talude de montante. Autoria propria (2019)

Esse tipo de manifestação ocorre, de acordo com o Manual de Segurança e Inspeção de Barragens (2002), devido a vegetação natural da área e a falta de manutenção.

Outra invasão de vegetação foi observada no enrocamento de pedras (Figura 15), na parte superior do talude (Figura 16), como também no talude de jusante (Figura 17).

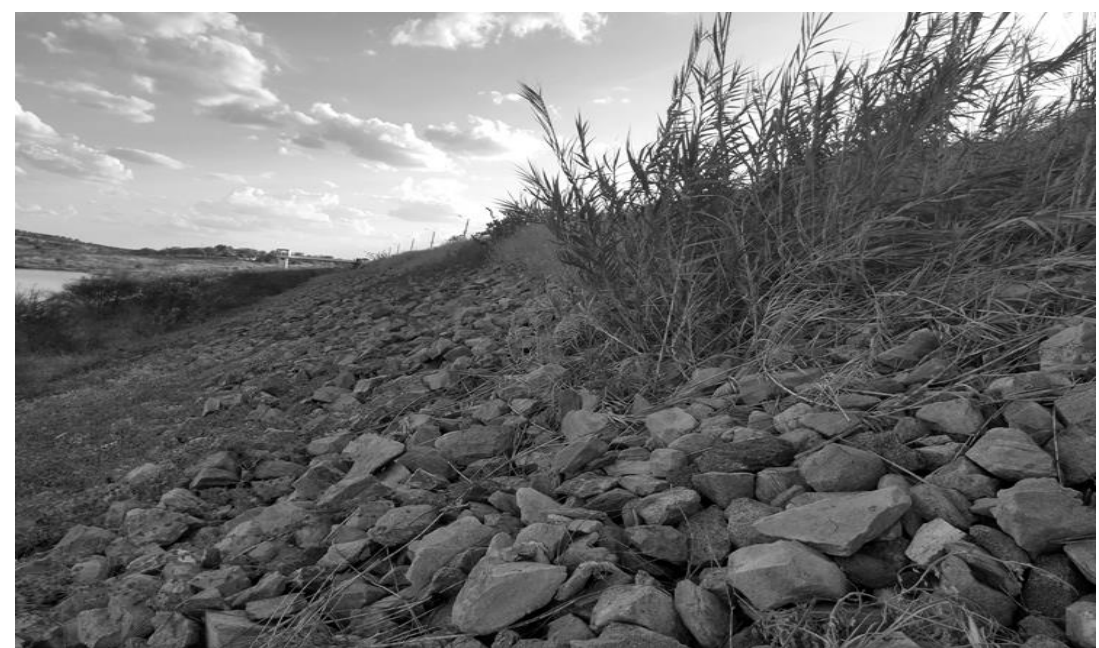

Figura 15: Surgimento de vegetação no enrocamento de pedra. Autoria própria (2019) 


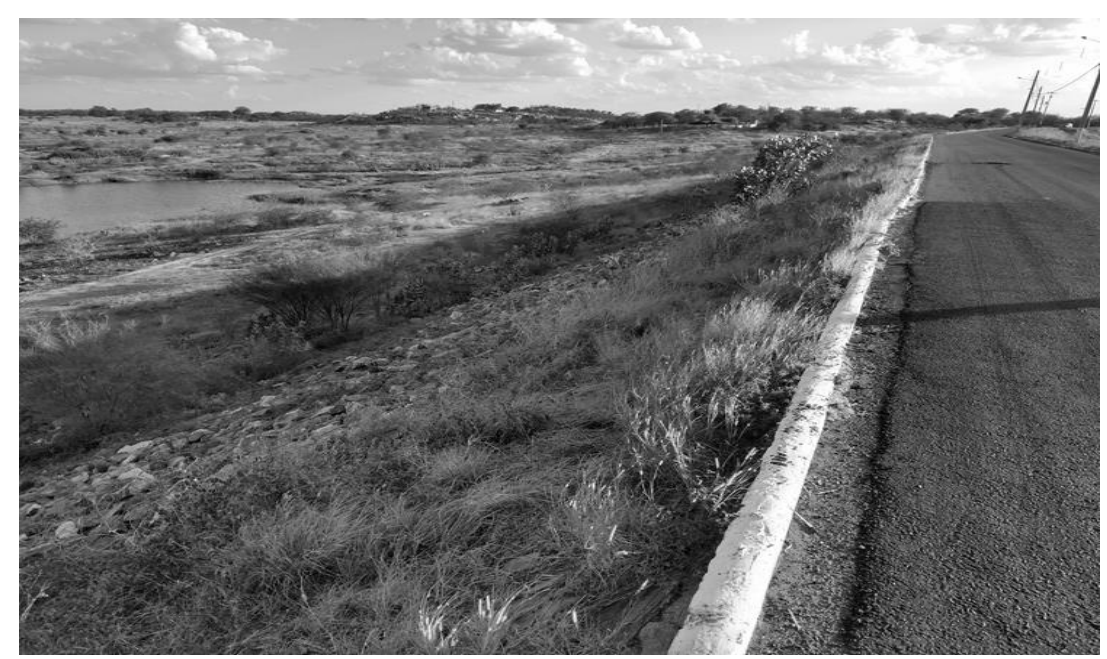

Figura 16: Vegetação na parte superior do talude. Autoria própria (2019)

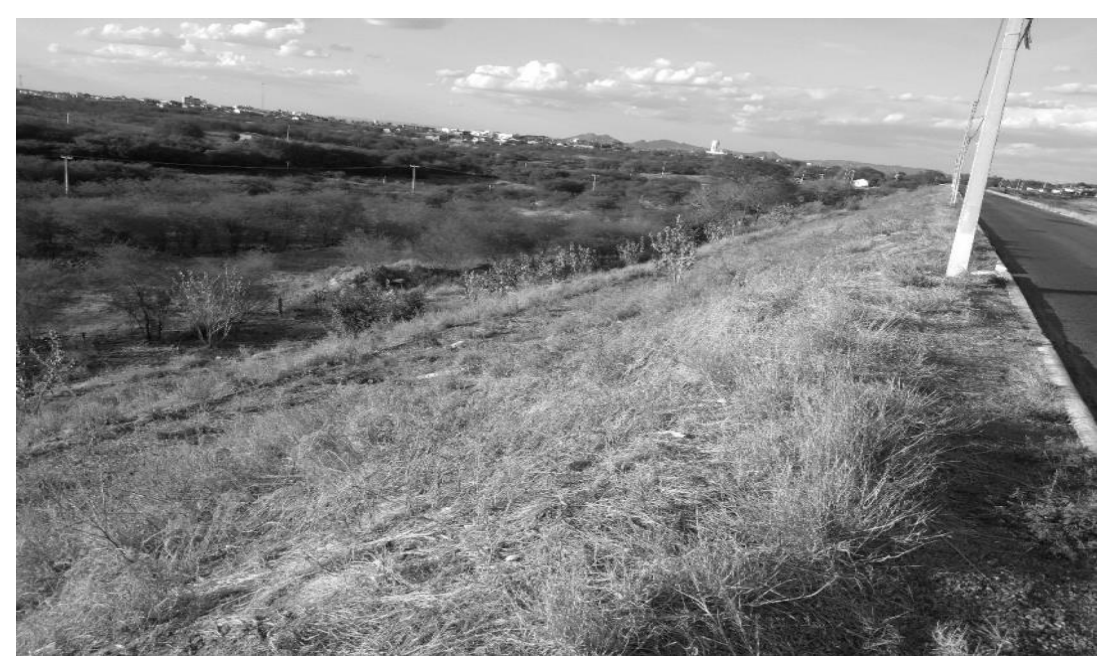

Figura 17: Presença de árvores e vegetação no talude de jusante. Autoria própria (2019)

Segundo ainda o mesmo autor, tem como possíveis consequências a criação de caminhos para passagem d'água, devido as raízes das árvores, como também a dificuldade da inspeção visual e ainda servir de moradia para animais. Os taludes precisam ter estabilidade sob qualquer condição de operação, sob todos os níveis de água para suportar com segurança os carregamentos extremos, assim como também as cargas normais do projeto.

\section{CONCLUSÕES}

Esse trabalho teve como objetivo principal realizar um levantamento das condições gerais da Barragem de Itans. Diante dos estudos teóricos e das condições de realização do trabalho pode-se considerar que:

- As informações do histórico construtivo mostraram que não houve praticamente mudanças na barragem ao longo desses 83 anos de existência.

- Verificou-se a existência de diversas anomalias presentes na crista da barragem, tais como, falhas, trincas e buracos na malha asfáltica, caneletas obstruídas e trincadas, meio fio danificado com trincas e quebrado.

- No talude de montante observou a presença excessiva de vegetação, como na parte superior e no enrocamento de pedras, com árvores de pequeno e médio porte.

- No talude de jusante observou também a presença excessiva de vegetação, com árvores de pequeno e médio porte. 
A Barragem de Itans representa, há vários anos, um papel muito importante na região do Seridó do Estado do Rio Grande do Norte, principalmente para o abastecimento de água da população de Caicó/RN e cidades vizinhas. Observou-se nesse trabalho que serviços simples de manutenção precisam ser realizados para que a mesma enfrente com segurança as possíveis cheias que virão com as fortes chuvas que a região está recebendo. Esses serviços podem simplesmente ser, a retirada da vegetação que está recobrindo os taludes de montante e jusante e reparos na malha asfáltica, caneletas e nos meios fios.

\section{REFERÊNCIAS}

ANA, Agência Nacional das Águas. Manual de Segurança e Inspeção de Barragem. Brasília: Ana, 2012.

ANA, Agência Nacional das Águas. Manual do Empreendedor sobre Segurança de Barragens: Guia de Orientação e Formulários para Inspeções de Segurança de Barragem. Brasília: Ana, 2016. 218 p.

CBDB, Comitê Brasileiro de Barragens. Apresentação das Barragens. 2013. Disponível em: <http://www.cbdb.org.br/5-38/Apresenta\%C3\%A7\%C3\%A3o\%20das\%20Barragens>. Acesso em: 29 nov. 2018.

CGEE (Centro de Gestão e Estudos Estratégicos). A questão da água no Nordeste. Disponível em: http://www.cgee.org.br/eventos/Agua_Nordeste/contextualizacao.htm

COSTA, Walter Duarte. Geologia de Barragens. São Paulo: Oficina de Texto, 2012.

LEMOS FILHO, Luís César de Aquino. Pesquisadores alertam para o perigo das barragens. Disponível em: <https://assecom.ufersa.edu.br/2019/02/19/pesquisadores-alertam-para-o-perigo-das-barragens/>. Acesso em: $11 \mathrm{dez}$. 2019.

SBB ENGENHARIA. Fissuras longitudinais na crista de uma barragem de terra instrumentada com pares de pinos. [2015]. Disponível em: http://biblioteca.ana.gov.br/index.asp?codigo_sophia=66095. Acesso em: 15 dez. 2019. 